open@ACCESS

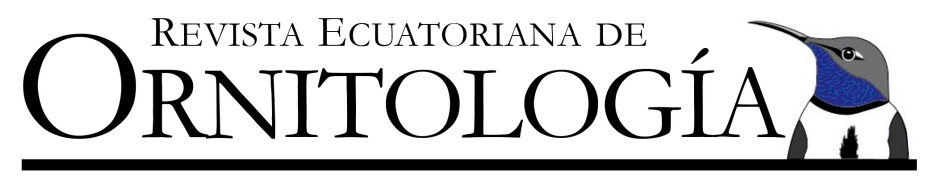

NOTAS DE CAMPO/FIELD NOTES

\title{
Chungüi Alicastaño Cinclodes albidiventris comiendo flores
}

\author{
Juan F. Freile \\ Comité Ecuatoriano de Registros Ornitológicos,e-mail: jfreileo@yahoo.com \\ Editado por/Edited by: Harold Greeney \\ Recibido/Received: 26 Marzo 2020. Aceptado/Accepted: 27 Agosto 2020 \\ Publicado en línea/Published online: 13 Diciembre 2020
}

La dieta de los chungüis, horneros, mineros y otros Furnariidae terrestres comprende pequeños invertebrados (escarabajos, hemípteros, larvas de mariposas, caracoles, moluscos, hormigas, arácnidos, lombrices), pequeños invertebrados en menor proporción y ocasionalmente semillas (Remsen, 2003).

En 14 abril 2010 observé un individuo de Chungüi Alicastaño Cinclodes albidiventris ingiriendo una flor de Disterigma sp., una ericácea terrestre de flores rastreras color rosa. La flor es coriácea y redonda, similar a una fruta. No existen reportes en la literatura de Cinclodes spp. alimentándose de flores, aunque Remsen (2003) menciona unas pocas especies en las que se ha reportado frutas en su dieta. Existe tan solo una observación adicional de un furnárido alimentándose de frutos: un Colaespina de Azara Synallaxis azarae comiendo frutos de Coriaria ruscifolia (N. Krabbe, no publ. 2019). De hecho, Remsen (2003) considera a Furnariidae como una de las familias con dietas más restringidas a invertebrados. En estudios de dietas de aves neotropicales se ha reportado el consumo de flores o frutas en proporciones muy bajas en especies primordialmente insectívoras (Durães \& Marini, 2005), pero su función en la dieta de estas especies ha sido poco estudiada.

\section{REFERENCIAS}

Durães, R., \& M.A. Marini, M.A. (2005). A quantitative assessment of bird diets in the Brazilian Atlantic forest, with recommendations for future diet studies. Ornitología Neotropical, 16(1), 65-83. URL: https://sora.unm.edu/sites/default/files/journals/on/v016n01/p0065-p0084.pdf

Remsen, J.V., Jr (2003). Ovenbirds (Furnariidae). In J. del Hoyo, A. Elliott, J. Sargatal, D.A. Christie, \& E. de Juana (Eds.), Handbook of the birds of the world (pp. 162-357) Barcelona, España: Lynx Edicions. 